\title{
INFLUÊNCIA DO CONDENSADO NO SISTEMA EGR
}

\author{
Marcio Henrique Leme Maia ${ }^{1}$, Agenor de Toledo Fleury ${ }^{1}$, Maurício Assumpção Trielli ${ }^{1}$, Jairo \\ de Lima Souza ${ }^{2}$, Luiz Roberto Nocciolini ${ }^{2}$ e Roberto Higa ${ }^{2}$ \\ ${ }^{1}$ Centro Universitário da FEI \\ ${ }^{2}$ Scania Latin America Ltda \\ E-mails: marcio.maia@fei.edu.br, agfleury@fei.edu.br, matrielli@fei.edu.br, \\ jairo.souza@scania.com, luiz.nocciolini@scania.com, roberto.higa@scania.com
}

\section{RESUMO}

As atuais exigências legais relativas à redução de emissões poluentes geradas por motores de ciclo diesel, tais como as relacionadas no Proconve 7 no Brasil, fazem com que seus fabricantes incluam e desenvolvam novas tecnologias ao motor e/ou aos dispositivos de póstratamento. Nas futuras propostas de legislações, os limites de emissão de óxidos de nitrogênio (NOx) e de material particulado (MP) para os motores diesel serão cada vez menores. A recirculação dos gases de escape (EGR) para o coletor de admissão é uma tecnologia muito utilizada entre as estratégias de redução de produção de NOx a nível dos cilindros. Apesar de vir sendo estudada há muito tempo, essa é uma técnica que apresenta ainda significativo potencial de aplicação, apesar de, via de regra, aumentar as emissões de MP e, devido à formação excessiva de condensado no sistema, acelerar a degradação dos componentes do motor. Este trabalho, por meio do uso de um arranjo que permite variar a produção de condensado no circuito de recirculação, busca correlacionar as produções de NOx e MP com a quantidade desse condensado presente na admissão do motor. Desta forma, pretende-se averiguar a possibilidade de controlar os parâmetros de recirculação de gases de escape de maneira a satisfazer as futuras exigências das legislações de emissões e ainda evitar a degradação do motor. Os resultados obtidos em diversos ensaios realizados com esse propósito são relacionados neste trabalho e discutidos com o intuito de avaliar o potencial ainda disponível para o dispositivo EGR na redução da produção de gases poluentes emitidos na atmosfera por motores diesel.

PALAVRAS-CHAVE: Motor Diesel, Emissões, EGR, Condensado.

\section{INTRODUÇÃO}

Ao longo da história, o grande desafio associado ao desenvolvimento de motores de combustão interna tem sido a eficiência energética. Nos dias de hoje, entretanto, soma-se a esse importante desafio, a crescente preocupação com as condições atmosféricas do planeta que faz com que o controle de emissões passe a ser um argumento adicional da função a otimizar.

Para atender as novas exigências de emissões, estratégias cada vez mais complexas são utilizadas no controle e gerenciamento dos sistemas do motor. O uso do EGR é uma das soluções que tem se mostrado eficiente no controle de emissões no que diz respeito à 
economia de recursos utilizados para tanto. Quando comparado com outras soluções como, por exemplo, com aquela que obriga o uso de solução de ureia no sistema SCR (Redução Catalítica Seletiva) de pós-tratamento em quantidade proporcional ao consumo do combustível, o uso do EGR reduz significativamente o custo operacional do veículo. Entretanto, surgem preocupações quando ele é utilizado: a durabilidade dos componentes do motor pode ser reduzida devido à agressividade dos compostos associados aos gases de recirculação que entram em contato com válvulas, cilindros, pistões e coletores de admissão e escape, além da contaminação do óleo lubrificante que circula, também, pelo bloco do motor.

A motivação para este trabalho tem como origem um estudo feito anteriormente que envolveu ensaios de motores utilizando combustíveis com diferentes concentrações de enxofre e que mostrou a agressividade da acidez do condensado, crescente com o teor de enxofre, e que definiu limites para a vida útil do motor por períodos considerados adequados [1] ao se utilizar um tipo especial de catalisador que reduzia a produção de ácidos de enxofre nos gases de recirculação. Esse trabalho reforçou a necessidade de investimento na qualidade do combustível que deve ser utilizado quando se opta por tecnologias como o EGR. Assim sendo, a investigação sobre a influência do volume de condensado nas emissões passou a ser importante e justificou a realização dos diversos testes que constituem este trabalho.

\section{OBJETIVO}

Os principais objetivos deste trabalho são avaliar as consequências do aumento de volume de condensado no sistema de Recirculação dos Gases de Exaustão (EGR) sobre as emissões e definir uma forma de controlar a passagem do condensado para o coletor de admissão.

Os parâmetros necessários para esse controle podem ser definidos e quantificados a partir de ensaios do motor que incluam diferentes condições de funcionamento do motor (torques e rotações).

Do ponto de vista conceitual, este trabalho avalia a influência das trocas de calor entre os gases de combustão e o líquido condensado na formação de NOx, material particulado (MP) e no consumo de combustível.

\section{PARTE EXPERIMENTAL}

Para atingir os objetivos propostos de avaliar a influência das trocas de calor entre os gases de combustão e o condensado na formação de NOx e de material particulado (MP), bem como na eficiência do motor, a metodologia para obtenção de dados incluiu as seguintes atividades:

a) Ensaio das diferentes configurações de montagem e regulação do sistema de arrefecimento dos gases de recirculação para obter as influências de cada componente modificado no arranjo, a saber:

(1) Ensaio com o motor em condições originais, ou seja, com o arranjo comercial;

(2) Ensaio com o cooler do EGR inclinado com passagem por separador de condensado;

(3) Ensaio com o cooler do EGR inclinado sem a passagem dos gases por separador de condensado; 
(4) Ensaios com 4 valores diferentes de volume de condensado na admissão obtidos com o uso de água a baixa temperatura como fluido de arrefecimento do cooler e vazões diferentes estabelecidas por meio de manobra de válvulas.

b) Medição do condensado gerado para diferentes condições de funcionamento do motor;

c) Medição das emissões produzidas para as diferentes quantidades de condensado presentes no ar de admissão nas diversas condições de funcionamento do motor;

d) Definição da vazão e da temperatura da água de arrefecimento utilizada no trocador de calor utilizado como condensador

Em todos os ensaios realizados, utilizou-se um mesmo motor SCANIA da série EURO 4 cujas características constam da Tabela 1. Sua instalação na bancada de testes é mostrada na Figura 1.

Tabela 1: Características do motor SCANIA da série EURO 4 utilizado nos ensaios

\begin{tabular}{|c|c|}
\hline Modelo & DC916 \\
\hline Número de cilindros & 5 \\
\hline Cilindrada total & $9 \mathrm{~L}$ \\
\hline Potência máxima & $169 \mathrm{~kW} @ 1.800 \mathrm{rpm}$ \\
\hline Torque máximo & $1.050 \mathrm{Nm} @ 1.200 \mathrm{rpm}$ \\
\hline Sistema de abatimento de NOx & EGR de um estágio de refrigeração \\
\hline
\end{tabular}

A bancada de testes era constituída por um freio dinamométrico ABB, modelo FQDI31.4-4WFI Euro VI, com capacidade máxima de frenagem de $620 \mathrm{~kW} @ 4.000 \mathrm{rpm}$ e para torque máximo de $3.200 \mathrm{Nm}$ e por um conjunto analisador de gases é de fabricação da AVL, modelo AMA I 60, do tipo FTIR (espectroscopia de infra-vermelho por Transformada de Fourier). Para a medição de particulado foi utilizado um Smart Sampler da AVL, modelo GEM 140.

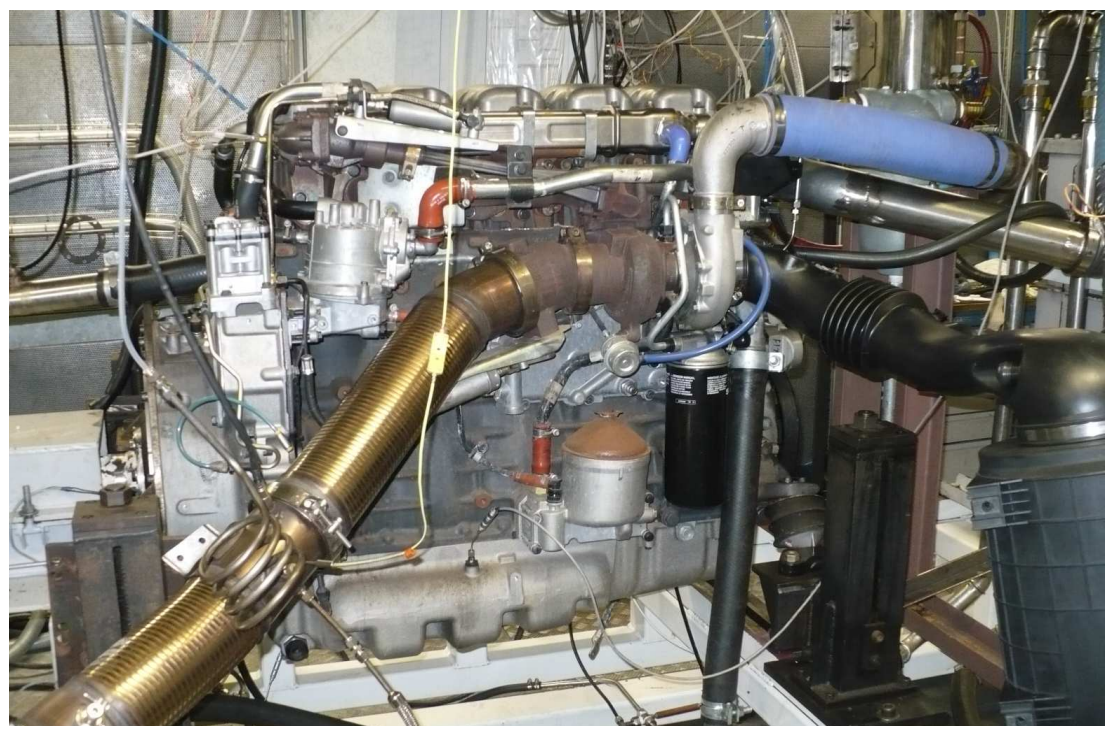

Figura 1 - Motor com configuração original montado na bancada de testes 
Todos os testes foram realizados com combustível B5 (óleo diesel com 5\% em volume de biodiesel) e com teor de enxofre inferior a 10 ppm (S10), como o disponível atualmente para comercialização no Brasil.

Os pontos de funcionamento do motor escolhidos para a definição da vazão de água de resfriamento do condensador e para comparação entre os efeitos resultantes das regulações de fluxos de gases pelo separador foram retirados do ciclo ESC (European Steady-State Cycle), utilizado na homologação de motores diesel no Brasil. Foram selecionados quatro pontos desse ciclo, conforme mostrados na Tabela 2.

Os pontos de máximo torque e de máxima potência (pontos $\mathrm{A}$ e $\mathrm{C}$, respectivamente) foram selecionados por gerarem maiores volumes de condensado devido à maior quantidade de combustível envolvido nas combustões. Os pontos B e D foram escolhidos para auxiliar a identificar aspectos associados ao mecanismo da formação de condensado em diferentes pontos de funcionamento em cargas parciais em diferentes rotações. Nesses pontos foram levantadas as produções específicas de NOx e MP para cada quantidade de condensado disponibilizado para a admissão.

Tabela 2- Pontos de Funcionamento

\begin{tabular}{|c|c|c|}
\hline Ponto & Rotação (rpm) & Carga (\%) \\
\hline A & 1200 & 100 \\
\hline B & 1200 & 50 \\
\hline C & 1800 & 100 \\
\hline D & 1800 & 50 \\
\hline
\end{tabular}

\subsection{Configurações utilizadas nos ensaios}

A configuração 1 utilizada nos ensaios corresponde àquela em que motor foi mantido nas condições originais em que foi submetido à homologação. $\mathrm{O}$ objetivo desse ensaio foi gerar uma referência para os valores de emissão de NOx, MP e consumo de combustível. A Figura 2 mostra essa configuração. 
(a)

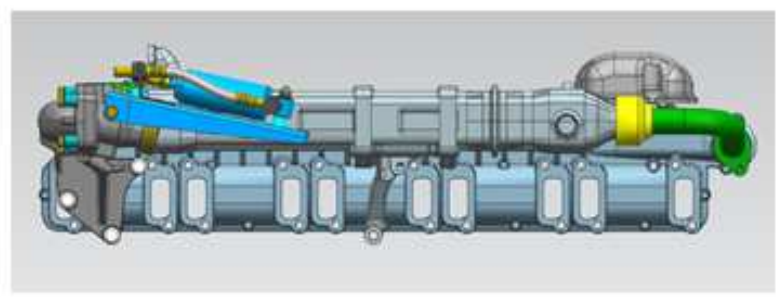

(b)

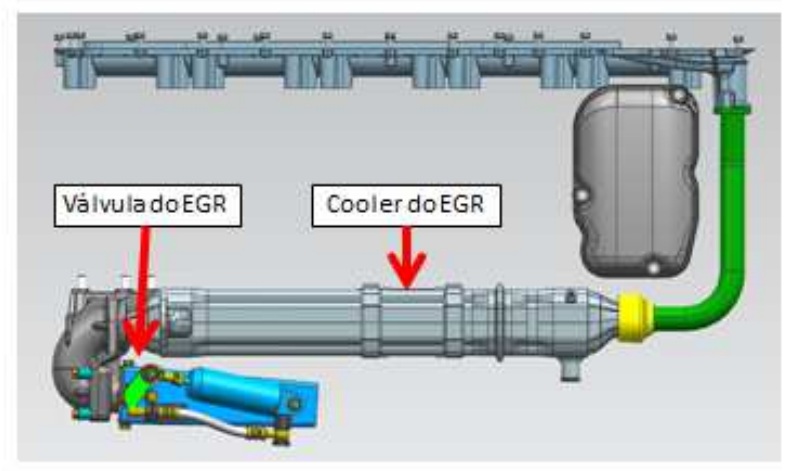

Figura 2 - Esquema da configuração original vista em elevação (a) e em planta (b)

A configuração 2 utilizada difere da primeira pela disposição inclinada do cooler do EGR e pela inclusão de separador gás/líquido, tubos, mangueiras e válvulas no circuito do gás de recirculação, como pode ser visto na Figura 3.

(a)

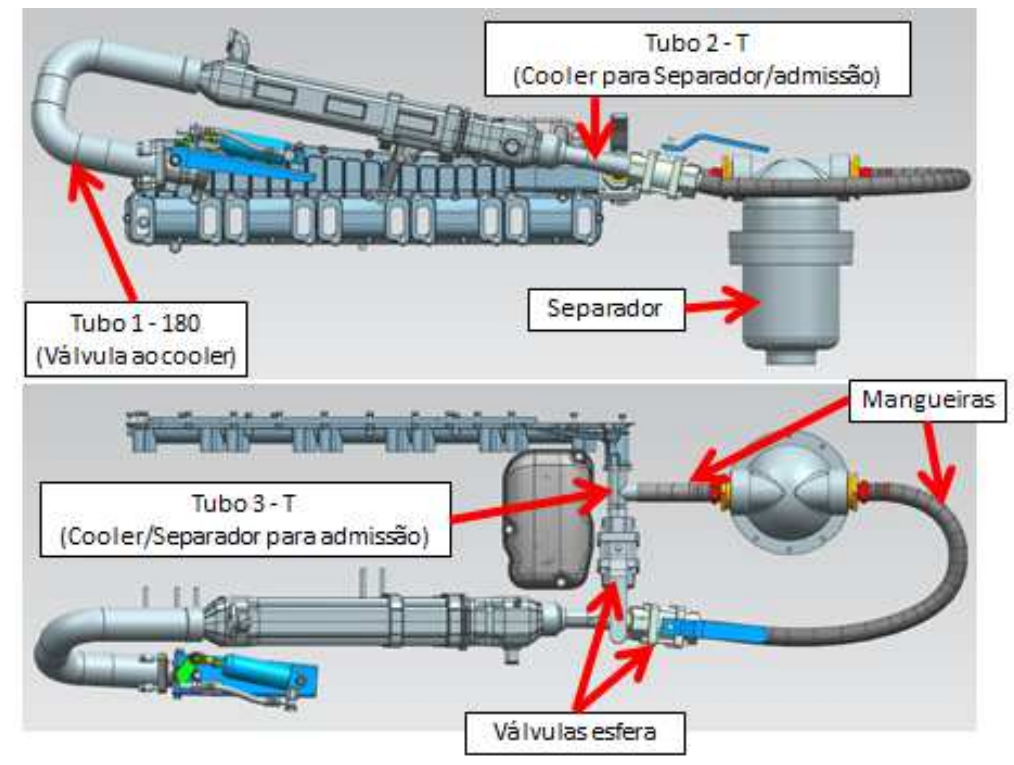

Figura 3- Esquema em elevação (a) e em planta (b) da montagem com cooler do EGR inclinado, válvulas, tubos, mangueiras e separador de condensado

O motivo da inclinação do cooler era evitar que o condensado se acumulasse na parte inferior do trocador de calor dos gases (cooler).

Buscava-se, nesse ensaio, avaliar a influência dos componentes incluídos no escoamento dos gases (perda de carga, p.e.) e nas emissões. 
A instalação dos sensores e válvulas foi feita de acordo com recomendações apropriadas, buscando garantir o controle de todo o sistema EGR e das interfaces de interferência.

Os componentes incluídos foram dispostos de forma a facilitar as medições do volume, além de não permitir o acúmulo de condensado. Essa configuração contou ainda com a montagem de um purgador de boia na saída de dreno onde o condensado é coletado. A Figura 4 mostra o sistema de purga do condensado após a saída do dreno no separador.

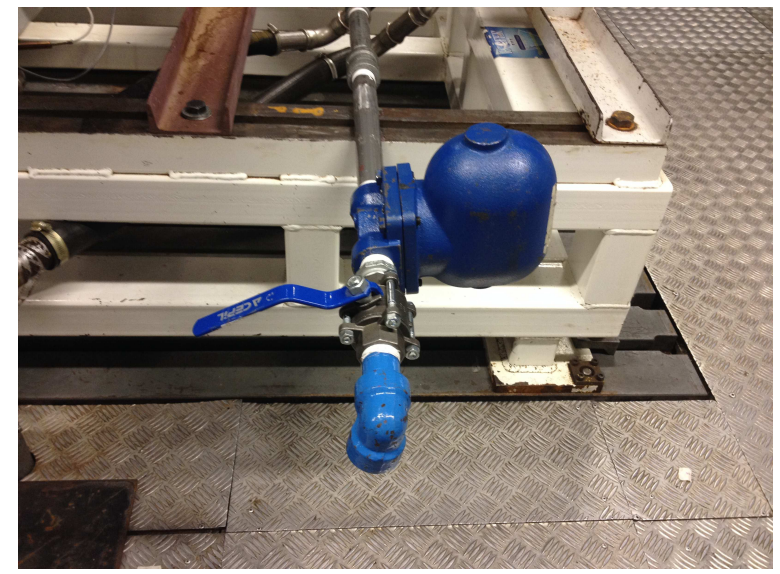

Figura 4 - Purgador

As válvulas foram manobradas de maneira que o fluxo dos gases proveniente do cooler do EGR circulasse pelo separador gás/liquido antes de chegar ao coletor de admissão.

$\mathrm{Na}$ configuração 3 dos ensaios, o separador gás/liquido, os tubos, as mangueiras e as válvulas permaneceram instalados nas mesmas condições do arranjo anterior. Nesses ensaios, o objetivo era isolar o separador e avaliar sua influência por meio de comparações feitas com os resultados do ensaio anterior. Para tanto, a válvula de entrada do separador (válvula com manopla azul na válvula V1) foi fechada e a válvula de by-pass do separador gás/líquido foi mantida aberta (válvula com manopla cinza na válvula V2). Assim, os gases do EGR eram integralmente direcionados para o coletor de admissão, sem passar pelo separador gás/líquido.

Visando explorar os efeitos do volume de condensado na admissão, quatro ensaios adicionais foram realizados. Esses ensaios, a montagem utilizada nos ensaios anteriores foi mantida. Entretanto, o arrefecimento do sistema EGR passou a ser realizado não mais com a água do motor e sim com água externa ao motor e à temperatura ambiente. Desta forma, maior quantidade de condensado seria gerada e, na sequencia, poderia ser separado do fluxo dos gases em diferentes quantidades. Essa configuração pode ser visualizada na Figura 5. 


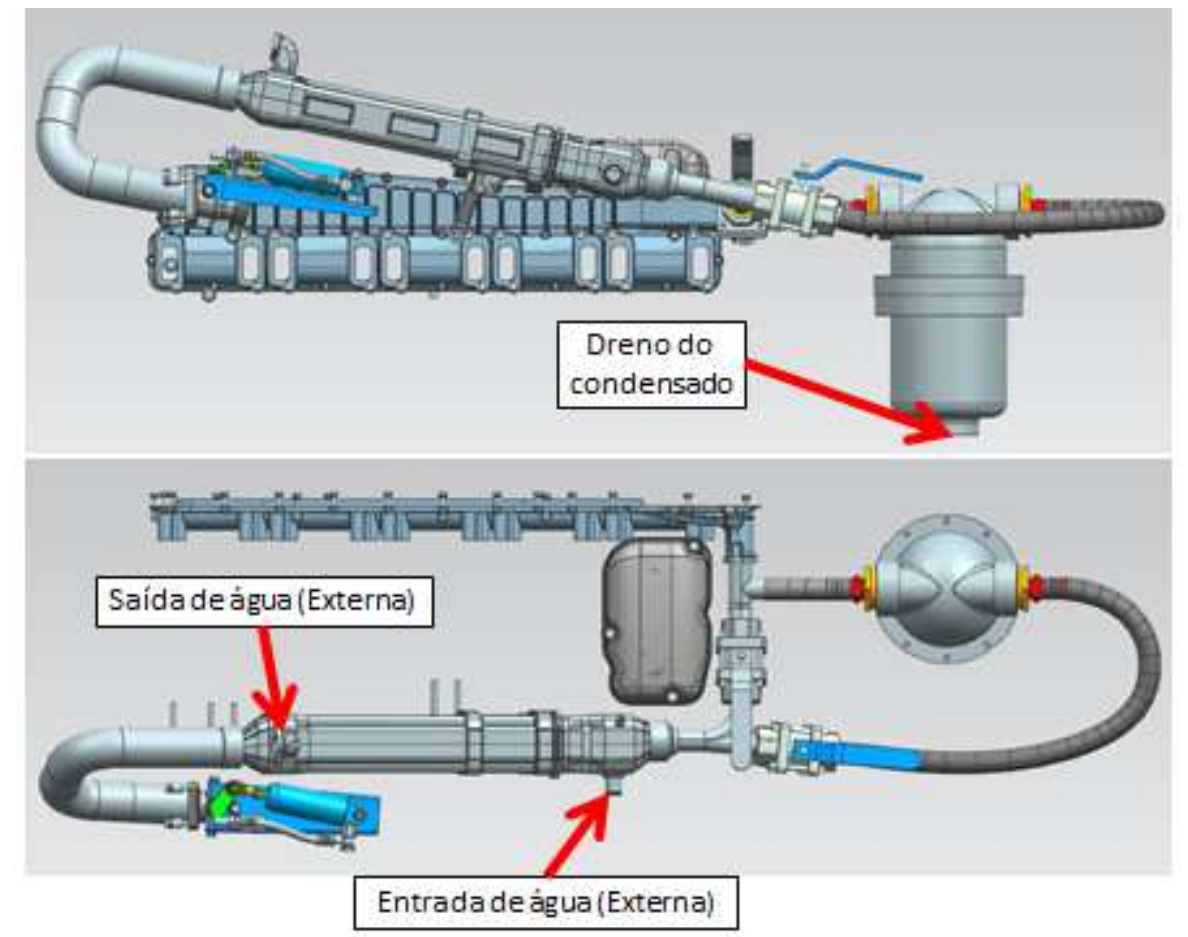

Figura 5 - Esquema do arrefecimento do cooler com água externa

A quantidade de condensado encaminhada para o coletor de admissão do motor foi dosada por meio da manobra das válvulas V1 e V2, como descrito a seguir:

No ensaio denominado como 4 daqui para frente neste texto, a válvula V1 foi mantida totalmente aberta e a válvula V2 foi mantida totalmente fechada, forçando todo o gás de recirculação a passar pelo separador. $\mathrm{O}$ objetivo era que o separador retivesse todo o condensado gerado no cooler do EGR.

No ensaio denominado como 5, a válvula V1 foi mantida totalmente aberta e a válvula V2 foi posicionada para ficar apenas aberta parcialmente (pela metade); isso possibilitava que uma parte do condensado passasse diretamente para a admissão.

No ensaio denominado como 6 , ambas as válvulas foram posicionadas de forma a ficarem abertas parcialmente pela metade; isso restringia a passagem do gás pelo separador e, consequentemente, permitia que uma parcela maior de condensado fosse a admissão.

Na última configuração, no ensaio denominado como 7, a válvula V1 foi totalmente fechada e a válvula V2 toda aberta; isso não permitia a passagem do gás pelo separador e todo o condensado era dirigido à admissão.

Foram registradas as temperaturas e pressões antes e depois do cooler do EGR em todas as configurações.

Nestes quatro testes foi possível analisar e quantificar a influência da admissão de condensado no sistema frente às emissões de NOx, material particulado (PM), bem como sobre o consumo específico do motor.

As temperaturas dos gases de recirculação, após a passagem pelo cooler arrefecido com água externa, reduziram-se significativamente nesses 4 últimos testes: 
- no ponto A, a temperatura média desses gases reduziu de $79^{\circ} \mathrm{C}$ para $26^{\circ} \mathrm{C}$;

- no ponto B, essa temperatura reduziu-se de $74^{\circ} \mathrm{C}$ para $22^{\circ} \mathrm{C}$;

- no ponto C, reduziu de $104^{\circ} \mathrm{C}$ para $59^{\circ} \mathrm{C}$, e

- no ponto $\mathrm{D}$, reduziu de $96^{\circ} \mathrm{C}$ para $44^{\circ} \mathrm{C}$.

\section{RESULTADOS EXPERIMENTAIS E DISCUSSÃO}

Os resultados de emissões obtidos para os pontos A, B, C e D são mostrados nas figuras numeradas de 6 a 9 para as diferentes configurações em que os ensaios foram realizados, bem como na Tabela 4. Para as configurações 4, 5, 6 e 7 foram informadas também as quantidades de condensado drenado.

O valor do condensado drenada no ponto A na configuração 7 , para o qual se esperava um valor nulo devido à posição das válvulas de controle de fluxo, foi de $42 \mathrm{ml}$. Isso pode ser explicado pelo fato de não ter sido prevista uma válvula que restringisse a entrada do gás pelo nó que se comunica com a saída do separador.

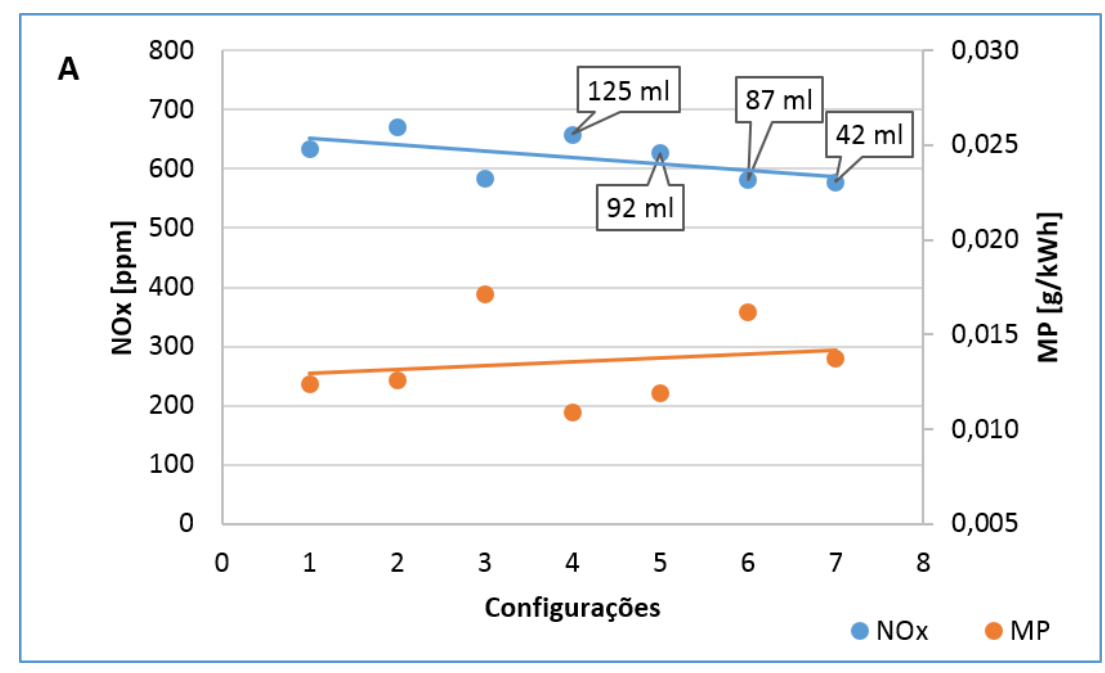

Figura 6 - Resultados de emissões obtidos no ponto A para as diferentes configurações 


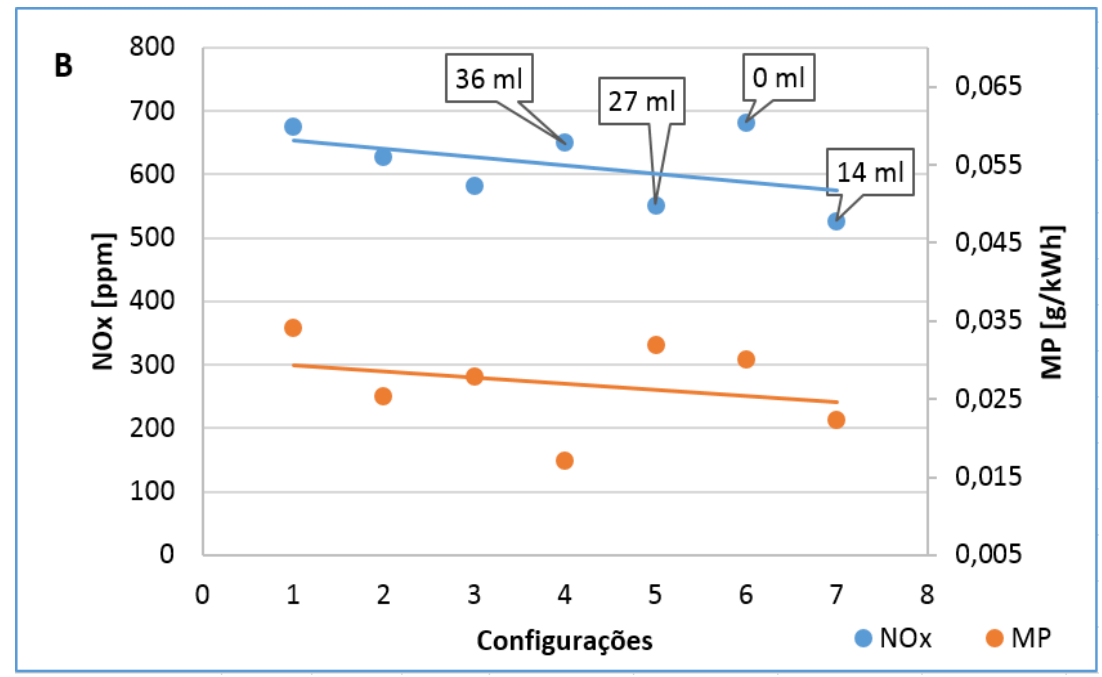

Figura 7 - Resultados de emissões obtidos no ponto B para as diferentes configurações

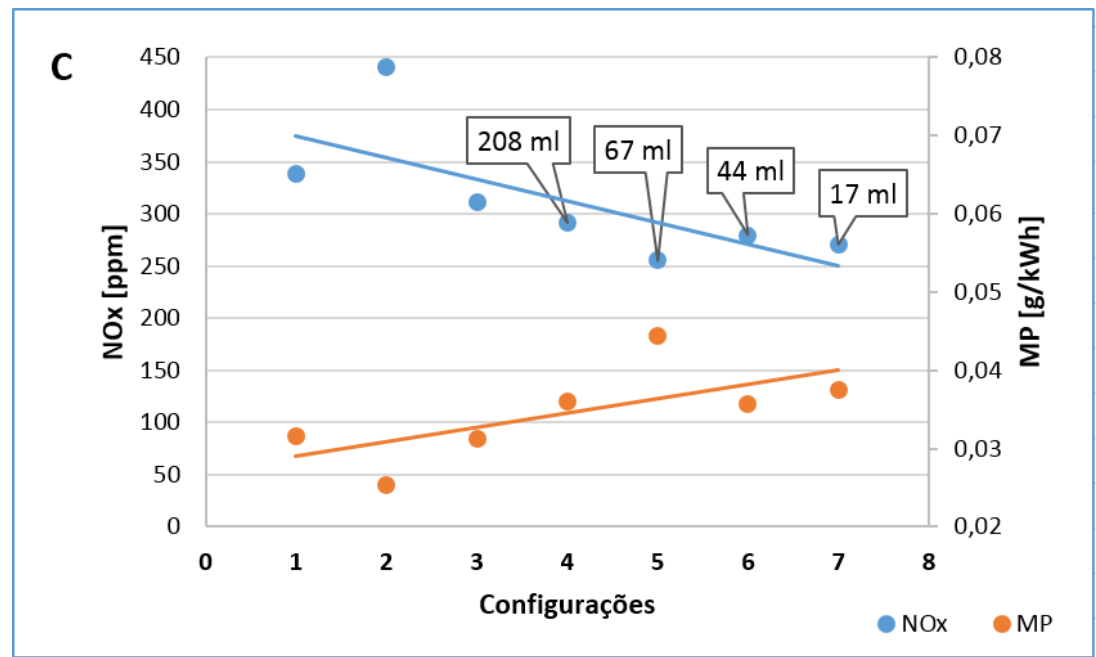

Figura 8 - Resultados de emissões obtidos no ponto $\mathrm{C}$ para as diferentes configurações

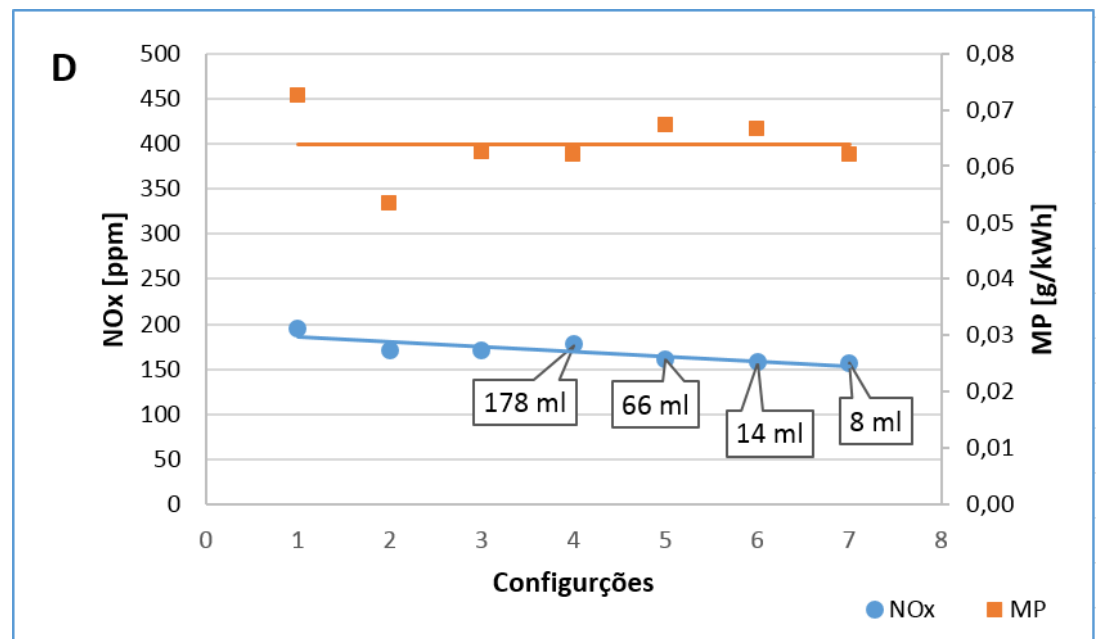

Figura 9 - Resultados de emissões obtidos no ponto D para as diferentes configurações 
A Tabela 3 fornece os resultados de desempenho obtidos durante os ensaios realizados nos 4 pontos (A, B, C e D), incluindo as incertezas das respectivas medidas para um nível de confiança de $95 \%$ ao se utilizar a distribuição t-Student.

Tabela 3: Resultados de desempenho

\begin{tabular}{|c|c|c|c|}
\hline Ponto & Potência $(\mathrm{kW})$ & $\begin{array}{c}\text { Consumo em massa de } \\
\text { combustível }(\mathrm{kg} / \mathrm{h})\end{array}$ & Consumo específico $(\mathrm{kg} / \mathrm{kW} . \mathrm{h})$ \\
\hline A & $132,1 \pm 0,5$ & $28,15 \pm 0,76$ & $0,213 \pm 0,006$ \\
\hline B & $66,2 \pm 0,6$ & $14,32 \pm 0,26$ & $0,216 \pm 0,003$ \\
\hline C & $174,1 \pm 1,6$ & $38,20 \pm 0,42$ & $0,219 \pm 0,001$ \\
\hline D & $87,1 \pm 0,8$ & $21,6 \pm 0,15$ & $0,248 \pm 0,004$ \\
\hline
\end{tabular}

A Tabela 4 apresenta os resultados obtidos para as concentrações de NOx nos gases de escapamento em ppm, medidas para todas as configurações e pontos ensaiados. Também se utilizou a distribuição t-Student para o cálculo das incertezas relacionadas (também com 95\% de nível de confiança).

Tabela 4: Concentrações de NOx nos gases de escapamento (em ppm)

\begin{tabular}{|c|c|c|c|c|c|c|c|}
\hline \multirow{2}{*}{ Ponto } & \multicolumn{7}{|c|}{ Configuração } \\
\cline { 2 - 8 } & 1 & 2 & 3 & 4 & 5 & 6 & 7 \\
\hline A & $633,4 \pm 11,0$ & $670,3 \pm 14,7$ & $583,6 \pm 17,3$ & $657,9 \pm 10,3$ & $627,7 \pm 12,7$ & $580,7 \pm 6,8$ & $577,8 \pm 7,7$ \\
\hline B & $675,2 \pm 89,0$ & $628,7 \pm 0,0$ & $582,3 \pm 17,2$ & $649,9 \pm 45,5$ & $552,2 \pm 71,4$ & $682,3 \pm 5,7$ & $527,1 \pm 112,1$ \\
\hline C & $338,1 \pm 5,9$ & $347,5 \pm 468,9$ & $311,2 \pm 0,6$ & $292,1 \pm 3,0$ & $255,5 \pm 21,7$ & $278,6 \pm 3,0$ & $270,6 \pm 3,9$ \\
\hline D & $195,1 \pm 1,6$ & $170,8 \pm 3,3$ & $171,3 \pm 2,8$ & $177,6 \pm 4,1$ & $160,7 \pm 4,9$ & $157,8 \pm 0,3$ & $156,7 \pm 11,2$ \\
\hline
\end{tabular}

Como pode ser observado na Tabela 3, o sistema eletrônico de dosagem de combustível do motor forneceu sempre vazões com valores esperados e incluídos dentro das incertezas de medição para todos os pontos ensaiados, independentemente da configuração utilizada. A maior variação observada desse parâmetro ocorreu no ponto A em que a incerteza não chegou a superar $2,7 \%$ do valor médio das medidas.

Observando que as potências efetivas também forneceram valores nominais incluídos dentro da pequena incerteza calculada, pode-se verificar que a variação da quantidade de condensado contido no ar de admissão não alterou o desempenho do motor de forma significativa.

Com os dados relacionados na Tabela 4, observa-se que quantidades crescentes de condensado no ar de admissão (crescente da configuração 4 para a configuração 7) estão associadas a uma tendência de redução da produção de NOx nos pontos explorados, quer de plena carga, quer de cargas parciais. A produção específica, obtida com o uso de fatores de correção que levam em conta basicamente a umidade do ar e a relação combustível-ar mas não apresentadas na Tabela 4, também corroboram essa tendência. 
Cumpre notar, entretanto, que nos pontos de plena carga, verifica-se a tendência de crescimento na produção de MP. Isso pode ser explicado pela redução na taxa de conversão de energia química em energia interna na etapa rápida da combustão com a redução da temperatura máxima na câmara de combustão, aumentando a parcela de conversão nas etapas de combustão por difusão e/ou residual [4].

É importante observar também que a configuração 3, por introduzir maior perda de carga relativamente à configuração original, reduz mais significativamente a vazão de gases de recirculação. Mesmo assim, como regra, gerou produções de NOx menores ou iguais aquelas observadas com o uso das configurações 1 e 2, superando o efeito do arrefecimento maior do cooler nas configurações 4, 5, 6 e 7 em várias oportunidades. As produções de material particulado aumentaram de forma compatível. Isso pode ser explicado por um maior tempo de troca de calor dos gases no cooler que, correspondentemente, facilita a formação de condensado.

As Figuras 10 e 11 informam os consumos específicos de combustível, juntamente com as concentrações de NOx, respectivamente para os pontos de plena carga e de cargas parciais.

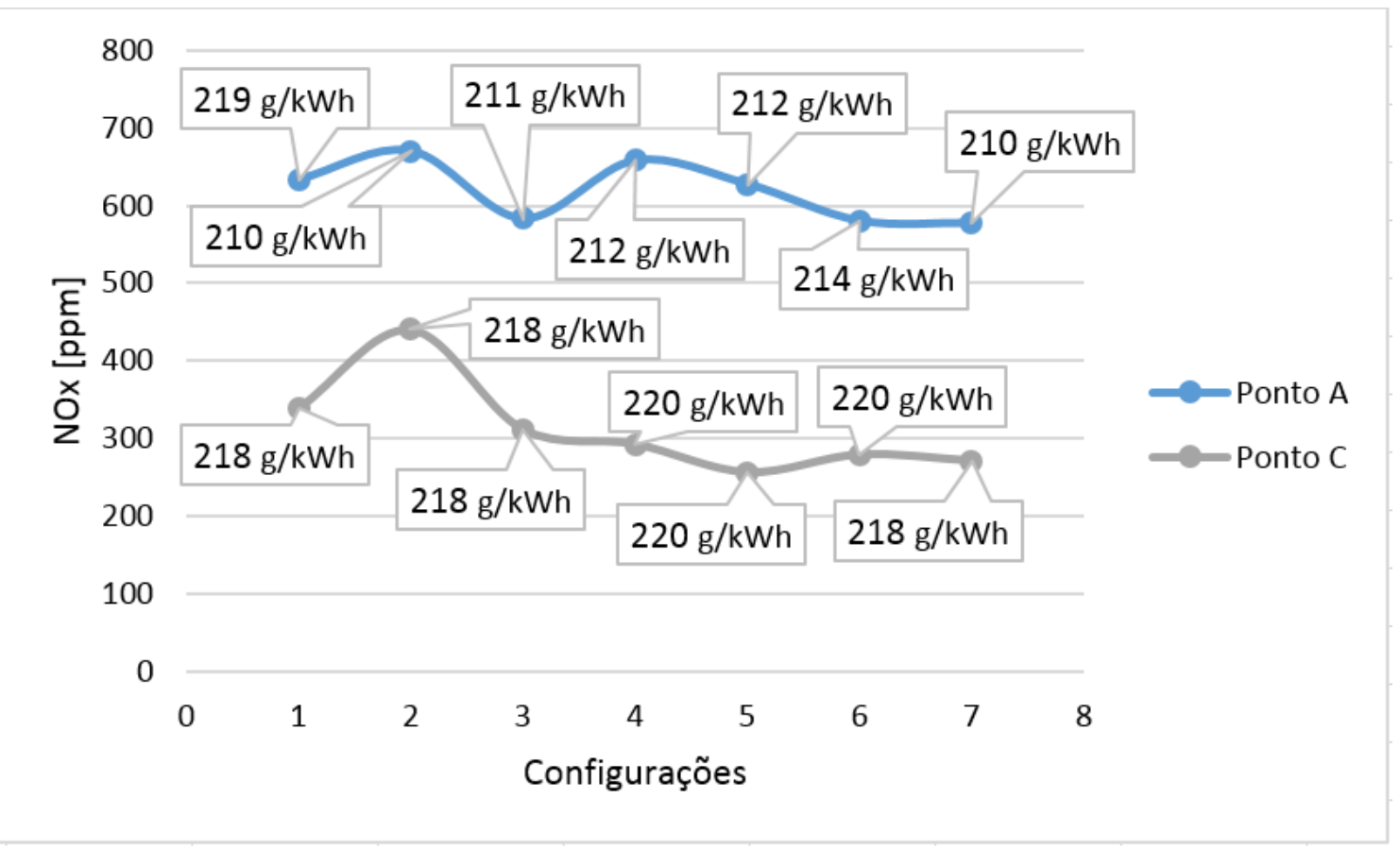

Figura 10 - Consumos específicos nos pontos A e C 


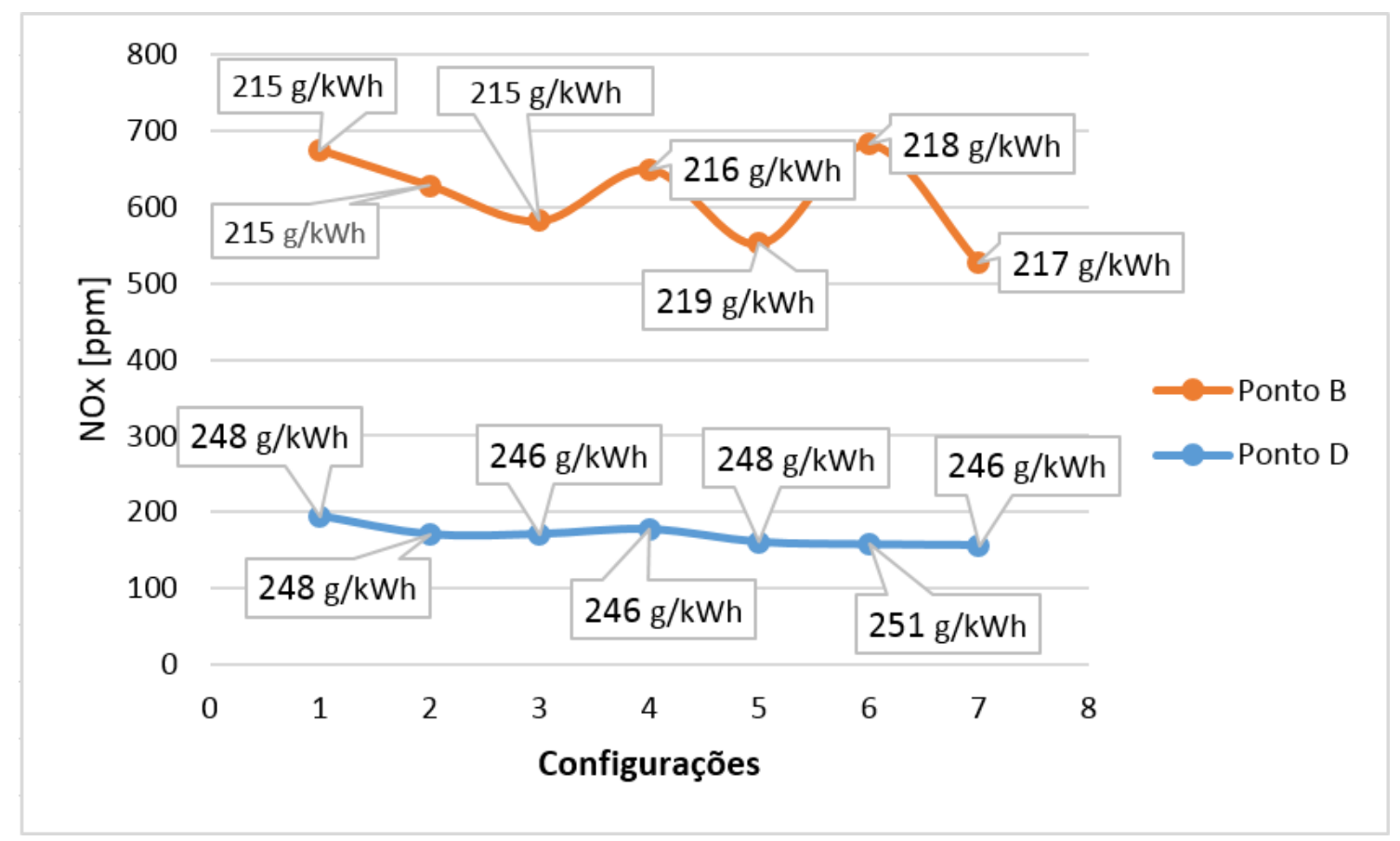

Figura 11 - Consumos específicos nos pontos B e D

\section{CONCLUSÕES}

Os efeitos sobre os escoamentos dos gases de recirculação do motor de aplicação automotiva de médio porte ensaiado, promovidos pelas restrições incluídas nas configurações ensaiadas e pela refrigeração forçada do EGR geraram concentrações diversas de condensado na admissão, como planejado.

O aumento da quantidade de condensado nos gases de recirculação gerou uma redução nas emissões de NOx nos pontos ensaiados, sem alterações de potência e de consumo horário de combustível. Essas reduções foram maiores em valor nominal nos pontos B e D de cargas parciais onde, também, foram observadas significativas reduções nas produções de MP.

Nos pontos A e C, de plena carga, também ocorreram significativas reduções de produção nominal de NOx (valores máximos de $9 \%$ e $22 \%$, respectivamente), porém, observou-se aumento nas emissões de MP em ambos os casos, como esperado. O uso de um filtro de particulado redimensionado poderia contornar esse problema e preservar o benefício conseguido no que tange à redução da produção de NOx. Entretanto, nessas condições de altas cargas é recomendável a retirada parcial do condensado pois, apesar de contribuir na redução das emissões, ele pode gerar degradação precoce do motor devido à acidez a ele associada e promovida pelo uso de combustíveis com altos teores de enxofre; os volumes de condensado formado são grandes na condição de máxima potência (chegando a 2,5L/h no caso estudado).

Conclui-se finalmente que a utilização do condensado é interessante para baixas cargas devido sua melhora não só para as emissões de NOx como também para as de MP e a viabilidade do uso do EGR resfriado fica condicionada à composição do combustível utilizado. Entretanto, o uso de combustíveis adequados pode fazer com que a técnica utilizada neste trabalho venha a gerar efeitos similares aos conseguidos, por exemplo, com injeção de água no coletor de admissão [6] ou utilizando um SCR como dispositivo de pós-tratamento. 


\section{REFERÊNCIAS}

[1] MUCHE, D. N. F. et al. Avaliação da Tecnologia EGR como solução para redução de emissões em motores diesel. XX Simpósio de Engenharia Automotiva, São Paulo, 25 Setembro 2012.

[2] BERGGREN, V. Condensation of Exhaust Gases in an EGR-cooler. KTH School of Industrial Engineering and Management. Stockholm, p. 80. 2008. (SE-100 44).

[3] MOLLENHAUER, K.; TSCHOEKE, H. Handbook of Diesel Engines. Berlin: Springer, 2010.

[4] HEYWOOD, J. B. Internal Combustion Engine Fundamentals. New York: McGrawHill Publishing, 1988.

[5] BRUNETTI, F. Motores de Combustão Interna. 3a . ed. São Paulo: Blucher, v. II, 2012.

[6] TAUZIA, ; MAIBOOM, A.; SAMIUR, S. R. Experimental study of inlet manifold water injection on combustion and emissions of an automotive direct injection Diesel engine. Elsevier, Nantes, v. 35, n. 9, p. 3628-3639, 9 Setembro 2010. 